\title{
The small, the hidden, the less-loved: conserving other species
}

\author{
MARTIN FisheR
}

How many species are there? It is a question of almost childlike simplicity. Yet despite extrapolations-from the proportion of known versus unknown species in surveys of tropical forests, or from modelling-the question awaits a satisfactory answer. To assess the degree to which species are threatened, and to conserve them, it is, however, selfevidently helpful to know their names and their number. We need a pragmatic way of answering our question to a first approximation. A tool to help with this is to hand, but let us go there by a less-tramped route.

Have you ever searched the Red List (IUCN, 2018a) for a species and found that its conservation status has not yet been assessed? Take Alhajarmyia umbraticola, for example, an obscure fly with a curious life style. It lives as a larva in fine sand in shallow caves or beneath shady rock overhangs, has no common name, is rare, endemic to the northern Oman mountains, and as far as I am aware has only been knowingly observed by two people. As the conservation status of our fly has not yet been assessed, our search on the Red List is redirected to its entry in the grandly namedand rightly so-Catalogue of Life (2019).

As of 20 February 2019 the Catalogue contains information on 1,836,304 living species in 101 phyla and seven kingdoms plus viruses. For many reasons this number, which includes only named living species and therefore may be low to the order of several million, does not answer our question but it does provide a useful perspective. Of these c. 1.8 million species, our obscure fly is one of $1,082,947$ species in the phylum Arthropoda, which comprise 59\% of all named species. Delving further into the Catalogue reveals that the oft-quoted comment attributed to J.B.S. Haldane -that the Creator is inordinately fond of beetles-still holds, with 327,920 named species of Coleoptera (c. $35 \%$ of named insects and c. $18 \%$ of all named species).

Our little-known species of fly-lonesome in its own genus in the family Vermileonidae, the worm lions-is one of 154,156 species of Diptera, the second-most speciesrich insect order, and one of the 919,928 insect species whose conservation status has yet to be assessed. Of the less than $1 \%$ of insect species that have been assessed for the Red List (IUCN, 2018b), 1,537 (c. 19\%) are categorized as threatened (i.e. in the categories Critically Endangered, Endangered or Vulnerable). This compares to c. $21 \%$ of

Martin Fisher Fauna \& Flora International, The David Attenborough Building Pembroke Street, Cambridge, CB2 3QZ, UK

E-mail martin.fisher@fauna-flora.org mammals, $14 \%$ of birds, $13 \%$ of reptiles, $32 \%$ of amphibians and $4 \%$ of plants categorized as threatened after assessment. Assessing the conservation status of nearly 1 million insects is a task requiring heroes, and progress is being made with many groups, including recently the odonates, bumble bees and some beetle genera. With more than $99 \%$ of insects yet to be assessed, however, it is impossible to know whether a figure of $19 \%$ of species threatened is representative, or not, of the class as a whole.

The so-called invertebrates (they are not a sound taxonomic grouping but rather a miscellany of phyla) receive relatively little coverage in generalist conservation journals. For example, despite the numerical dominance of beetles, on only one occasion, to my knowledge, has a member of this order been the explicit subject of research published in Oryx, and in this case because it was causing havoc with a survey of the jaguar: dung beetles were tidying up most of the jaguars' scats before the researchers could collect them (Norris \& Michalski, 2010).

To help bring the invertebrates into better focus, authors in this issue of Oryx consider representatives of three phyla (one species of platyhelminth, one mollusc, and two arthropods). Our intention is epitomized by the title of the lead article: Even worms matter (Manenti et al., 2019). The authors describe successful habitat restoration for the 73 known individuals of another shade-loving species: a planarian platyhelminth endemic to a water pool within a single cave in northern Italy.

As a phylum, the molluscs, with 64,092 species (c. $4 \%$ of all species), have received proportionally more conservation attention than most other invertebrates: of 8,627 species assessed (c. 13\% of all molluscs) 2,195 species (c. 25\%) are categorized as threatened. In Oryx the endemic snails of the Galápagos (Coppois \& Wells, 1987), Polynesia (Coote et al., 1999; Coote \& Loève, 2003; Lee et al., 2008; Bick et al., 2016), Príncipe in the Gulf of Guinea (Dallimer \& Melo, 2010) and Manus Island off Papua New Guinea (Whitmore, 2016) have received attention. Ng et al. (2019) continue this theme, but with a twist, showing how a snail species presumed native to the Malay peninsula and categorized as Least Concern on the Red List, may rather be native to Singapore and is almost certainly threatened.

Amongst the arthropods we have to commend the confusingly named and evolutionarily ancient horseshoe crabs, which are not closely related to what we commonly know as crabs: the conservation status of all four species in this class has been assessed. Using the Wisdom of Crowds survey 
technique, Liao et al. (2019) examine two of the Asian species assessed as Data Deficient on the Red List, revealing a decline. This group now has its own IUCN Specialist Group, and the four species are currently being reassessed.

In the race to save species, it is easy to lose sight of what we know of ecology. This is neatly illustrated by Bröder et al. (2019), who demonstrate how the decline of another arthropod, a Critically Endangered grasshopper, appears to be driven by sheep grazing: ecology and conservation cutting across phyla. Yet the conservation of insects, despite their provision of valuable services such as pollination and decomposition, and their work as agricultural assistants forestalling crop-trampling elephants (Scheijen et al., 2019), is woefully neglected. Reports of widespread insect declines (Kosior et al., 2007; Leather, 2018; Sánchez-Bayo \& Wyckhuys, 2019) are now, however, throwing this group into sharp focus (Carrington, 2019).

Although we do not yet have a full count of living species, we do know that the small, hidden, less-loved creatures-the other species-vastly outnumber those we know well. Yet these less-loved species have an image problem that seems to render them largely invisible beyond specialist journals. Proportionally few have been assessed for the Red List, and relatively little funding is available for research on these groups (Leather, 2018). From microbes (Cockell \& Jones, 2009) to parastic lice (Rózsa \& Vas, 2015) and beyond we need to broaden our conservation vision if we are to tackle the mission we have chosen to accept.

This issue of Oryx is dedicated to the memory of Tony Whitten-cherished friend and colleague, and member of the Oryx International Board of Editors-who worked tirelessly for conservation, and especially for less-loved species and caves. In the next issue we will be announcing a series of awards for young conservation professionals in his memory.

This Editorial and the Oryx articles cited herein are freely available as a virtual issue of the journal at cambridge.org/ core/journals/oryx/virtual-issues.

Acknowledgements I thank Andrew Balmford, Bill Adams, Craig Hilton-Taylor, Emma Muench, Julia Hochbach, Maria Luisa de Castro Fisher and Simon Leather for their comments.

\section{References}

Bı́к, C.S., FoIghil, D.Ó. \& Coоте, T. (2016) Differential survival among Tahitian tree snails during a mass extinction event: persistence of the rare and fecund. Oryx, 50, 169-175.

Bröder, L., Tatin, L., Danielczak, A., Seibel, T. \& Hochkirch, A. (2019) Intensive grazing as a threat in protected areas: the need for adaptive management to protect the Critically Endangered Crau plain grasshopper Prionotropis rhodanica. Oryx, $53,239-246$.
Carrington, D. (2019) Plummeting insect numbers 'threaten collapse of nature'. The Guardian. Https://www.theguardian.com/ environment/2019/feb/10/plummeting-insect-numbers-threatencollapse-of-nature [accessed 21 February 2019].

Catalogue of Life (2019) Catalogue of Life. Http://www.catalogueoflife. org [accessed 21 February 2019].

Cockell, C.S. \& Jones, H.L. (2009) Advancing the case for microbial conservation. Oryx, 43, 520-526.

Coote, T. \& Loève, É. (2003) From 61 species to five: endemic tree snails of the Society Islands fall prey to an ill-judged biological control programme. Oryx, 37, 91-96.

Coote, T., Loeve, E., Meyer, J.-Y. \& Clarke, D. (1999) Extant populations of endemic partulids on Tahiti, French Polynesia. Oryx, 33, 215-222.

Coppois, G. \& Wells, S. (1987) Threatened Galápagos snails. Oryx, $21,236-241$.

Dallimer, M. \& Melo, M. (2010) Rapid decline of the endemic giant land snail Archachatina bicarinata on the island of Príncipe, Gulf of Guinea. Oryx, 44, 213-218.

IUCN (2018a) The IUCN Red List of Threatened Species. Https://www. iucnredlist.org [accessed 20 February 2019].

IUCN (2018b) Summary statistics. The IUCN Red List of Threatened Species. Https://www.iucnredlist.org/resources/summary-statistics [accessed 20 February 2019].

Kosior, A., Celary, W., Olejniczak, P., Fijal, J., Król, W., Solarz, W. \& Plonka, P. (2007) The decline of the bumble bees and cuckoo bees (Hymenoptera: Apidae: Bombini) of Western and Central Europe. Oryx, 41, 79-88.

Leather, S.R. (2018) "Ecological Armageddon"-more evidence for the drastic decline in insect numbers. Annals of Applied Biology, $172,1-3$.

Lee, T., Meyer, J.-Y., Burch, J.B., Pearce-Kelly, P. \& Ó Foighil, D. (2008) Not completely lost: two partulid tree snail species persist on the highest peak of Raiatea, French Polynesia. Oryx, $42,615-619$.

Liao, Y., Hsieh, H.-L., Xu, S., Zhong, Q., Lei, J., Liang, M. et al. (2019) Wisdom of Crowds reveals decline of Asian horseshoe crabs in Beibu Gulf, China. Oryx, 53, 222-229.

Manenti, R., Barzaghi, B., Tonni, G., Ficetola, G.F. \& Melotto, A. (2019) Even worms matter: cave habitat restoration for a planarian species increased environmental suitability but not abundance. Oryx, 53, 216-221.

NG, T.H., Tan, S.K., Ahmad, A., Tu, D.V., Joshi, R.C., WanG, W.Y., et al. (2019) Not in the Least Concern: anthropogenic influences on a South-east Asian apple snail Pila scutata (Ampullariidae). Oryx, $53,230-238$.

Norris, D. \& Michalski, F. (2010) Implications of faecal removal by dung beetles for scat surveys in a fragmented landscape of the Brazilian Amazon. Oryx, 44, 455-458.

RózsA, L. \& VAs, Z. (2015) Co-extinct and critically co-endangered species of parasitic lice, and conservation-induced extinction: should lice be reintroduced to their hosts? Oryx, 49, 107-110.

Sánchez-Bayo, F. \& Wyckhuys, K.A.G. (2019) Worldwide decline of the entomofauna: A review of its drivers. Biological Conservation, $232,8-27$.

Scheijen, C.P.J., Richards, S.A., Smit, J., Jones, T. \& Nowak, K. (2019) Efficacy of beehive fences as barriers to African elephants: a case study in Tanzania. Oryx, 53, 92-99.

Whitmore, N. (2016) Harnessing local ecological knowledge for conservation decision making via Wisdom of Crowds: the case of the Manus green tree snail Papustyla pulcherrima. Oryx, 50, 684-692. 